\title{
Exploring the coordination chemistry of imidoyl amidine ligands with first row transition metals
}

\author{
Raúl Castañeda, Bulat Gabidullin and Jaclyn L. Brusso \\ Department of Chemistry and Biomolecular Sciences, University of Ottawa, 10 Marie Curie, Ottawa, \\ Ontario K1N 6N5, Canada.
}

Metallic complexes and clusters formed between metals and organic ligands such as polypyridines have a broad range of applications as catalysts, molecular magnets and photosensitizers to name a few. One of the key factors that determine the properties of these complexes is the ligand selection. For example, ligands enable control of the electronic environment of a metal ion, and can also make possible the building of extended architectures with multiple metal centers. In that regard, the ligands $N$-2-pyridylimidoyl-2-pyridylamidine (Py2 ImAm) and $N$-2-pyrimidylimidoyl-2pyrimidylamidine (Pmz ImAm), which were recently synthesized by our group, offer the unique potential to coordinate in both a bidentate and tridentate coordinating sites. In an attempt to understand the coordination chemistry of $\mathbf{P y}_{2} \mathbf{I m A m}$ and $\mathbf{P m} \mathbf{I m A m}$, several complexes with utilizing $\mathrm{Mn}, \mathrm{Fe}$, or Co have been synthesized. Our results indicate that the key factor dictating which coordination site of $\mathbf{P y} \mathbf{y}_{2} \mathbf{I m A m}$ or $\mathbf{P m}_{2} \mathbf{I m A m}$ the metal ion prefers is the presence (or absence) of a weak acid. More specifically, the presence of a weak acid directs the metal ion to the tridentate site, while neutral or basic conditions lead to coordination complexes in which the metal center is bound to the bidentate pocket. By employing weakly acidic pyridinium counterions and controlling the solvent choice it was also possible to make homometallic clusters with $\mathbf{P m} \mathbf{I m} \mathbf{I m}$. Twelve new metallic complexes have been synthesized and characterized by single crystal X-ray diffraction. The magnetic susceptibility of the clusters obtained was also obtained and demonstrated an uncommon combination of spin states in the clusters characterized. Overall, both Py2ImAm and PmzImAm show very interesting acid-base chemistry and the characterization of new homometallic clusters is now underway.<smiles>N=C(NC(=N)c1ccccn1)c1ccccn1</smiles>

$\mathbf{P y}_{2} \operatorname{ImAm}$<smiles>N=C(NC(=N)c1ncccn1)c1ncccn1</smiles>

$\operatorname{Pm}_{2} \operatorname{ImAm}$ 